Research Paper: Pathology

\title{
TSH inhibits SERCA2a and the PKA/PLN pathway in rat cardiomyocytes
}

\author{
Jiajia Dong ${ }^{1}$, Cuixia Gao ${ }^{2}$, Jing Liu ${ }^{1}$, Yunshan $\mathrm{Cao}^{3}$ and Limin Tian ${ }^{1}$ \\ 1 Department of Endocrinology, Gansu Provincial Hospital, Lanzhou, Gansu, China \\ 2 Department of Ultrasonic Diagnosis, Gansu Provincial Hospital, Lanzhou, Gansu, China \\ ${ }^{3}$ Department of Cardiology, Gansu Provincial Hospital, Lanzhou, Gansu, China \\ Correspondence to: Limin Tian, email: tIm7066@sina.com \\ Keywords: TSH, SERCA2a, cardiomyocyte, PLN, PKA, Pathology Section \\ Received: November 10, $2015 \quad$ Accepted: April 16, 2016 \\ Published: May 16, 2016
}

\section{ABSTRACT}

Elevated thyroid-stimulating hormone (TSH) levels often accompany impaired LV diastolic function and subtle systolic dysfunction in subclinical hypothyroidism (sHT). These cardiac dysfunctions are characterized by increases in mean aortic acceleration and pre-ejection/ejection time ratios. To explore the mechanism underlying these pathologies, we investigated the effects of TSH on sarcoplasmic reticulum calcium ATPase (SERCA2a) activity and expression in neonatal rat cardiomyocytes. TSH inhibited SERCA2a activity and expression by binding to TSH receptors in cardiomyocyte membranes and inhibiting the protein kinase A/phoshpolamban (PKA/ PLN) signaling pathway. These results suggest that increases in serum TSH levels contribute to the development of cardiac diastolic and systolic dysfunction.

\section{INTRODUCTION}

Hypothyroidism is characterized by elevated serum thyroid stimulating hormone (TSH) concentrations and reduced concentrations of free T4. Several studies show that hypothyroidism changes myocardial oxygen consumption, cardiac output, and cardiac contractility, resulting in decreased heart output along with a prolonged isovolumic relaxation phase. Some of these cardiovascular symptoms result from the impact of thyroid hormone on the cardiovascular system [1].

Interestingly, we found that the risk of these cardiovascular events is also increased in subclinical hypothyroidism (sHT), which is defined by elevated serum TSH with normal free thyroid hormone levels. In sHT, the most common cardiac abnormality is an impairment in LV systolic function, characterized by increases in mean aortic acceleration and pre-ejection/ejection time ratio both at rest and during exercise [2,3]. Similarly, sHT is also associated with diastolic dysfunction, characterized by impaired early ventricular filling and slowed myocardial relaxation at rest that becomes more pronounced during exercise [4-7]. Conventional echocardiography and videodensitometric analysis confirmed that myocardial contractility is reduced and both the active and passive phases of diastole are dysregulated in sHT, as indicated by the following: (a) a lower cyclic variation index (CVI) in sHT indicated altered myocardial intrinsic contractility; (b) lower systolic strain and strain rate revealed an impairment of myocardial regional deformability; (c) an increase in peak $\mathrm{A}$ and decrease in peak $\mathrm{E}$ mitral flow velocity that resulted in a decline in left ventricular diastolic function [8].

Caraccio et al. described how long-term increases in serum TSH concentration contribute to the development of sHT [9]; TSH alone negatively impacted cardiac function, independent of HT. Moreover, exposure to slightly elevated TSH levels may, over time, contribute to systolic and diastolic abnormalities in sTH. These abnormalities often stem from changes in calcium homeostasis caused by altered expression or function of calcium transport or binding proteins. One such protein, cardiac sarcoplasmic reticulum calcium ATPase (SERCA2a), is a crucial for both cardiac contractility and the restoration of cytosolic calcium concentration during relaxation. The purpose of this study was to explore whether and how TSH regulates the expression of SERCA2a in neonatal rat cardiomyocytes. A better understanding of the cellular effects of TSH on the heart and cardiovascular system may contribute to the treatment of cardiac contractility and relaxation abnormalities associated with $\mathrm{sHT}$. 


\section{RESULTS}

\section{Neonatal rat cardiomyocyte isolation}

Cardiomyocytes were separated from cardiac fibroblasts with a differential sticking wall method. Twenty hours after plating, automobile pulsing was visible in the adhered cardiomyocytes. To determine the purity of cardiomyocytes, we examined $\alpha$-actinin antibody staining in the cells using immunofluorescence [11] (Figure 1).

\section{TSH receptor (TSHR) in NRCMs}

Although a distinct TSHR protein band was present in western blots from NRCM cells, the TSHR protein level was lower in NRCM cells than in positive control FRTL-5 cells; the TSHR band was not present in negative control $\mathrm{CHO}$ cells (Figure $2 \mathrm{~b}$ ). Immunofluorescent microscopy confirmed the presence of TSHR protein (red) in NRCM cell membranes (Figure 2a).

\section{TSH suppressed SERCA2a expression in NRCMs}

To explore the effect of TSH on ventricular SERCA2a expression in vitro, neonatal rat cardiomyocytes were treated with $4 \mu \mathrm{M}$ TSH for different periods of time. Real-time PCR revealed that SERCA2a mRNA expression decreased by $22.01 \%$ in response to 12 hours $(p<0.05)$, $41.24 \%$ in response to 24 hours $(p<0.001)$, and $54.56 \%$ in response to 48 hours $(p<0.001)$ of TSH treatment compared to the 6-hour control treatment (Figure 3a). SERCA2a protein levels also decreased in a timedependent manner after treatment (Figure 3b).

Cardiomyocytes were then treated with various concentrations of TSH for 48 hours. Real-time PCR showed that SERCA2a mRNA expression decreased by $13.09 \%$ in response to $2 \mu \mathrm{M}(p<0.05), 24.13 \%$ in response to $4 \mu \mathrm{M}(p<0.01)$, and $46.39 \%$ in response to $8 \mu \mathrm{M}(p<0.001) \mathrm{TSH}$ compared to the control $0 \mu \mathrm{M}$ treatment (Figure 3c). Western blot showed that SERCA2a protein levels also decreased in a dose-dependent manner after treatment (Figure 3d).

\section{TSH suppressed SERCA2a activity in NRCMs}

SERCA2a activity decreased dose-dependently relative to maximal ATPase activity after 48 hours of treatment with $2 \mu \mathrm{M}\left(65.1 \pm 6.6 \mathrm{nmol} \cdot \mathrm{mg}^{-1} \cdot \mathrm{min}^{-1}\right)(p<$ $0.05), 4 \mu \mathrm{M}\left(48.5 \pm 7.2 \mathrm{nmol} \cdot \mathrm{mg}^{-1} \cdot \mathrm{min}^{-1}\right)(p<0.01)$, or 8 $\mu \mathrm{M}\left(33.6 \pm 4.5 \mathrm{nmol} \cdot \mathrm{mg}^{-1} \cdot \mathrm{min}^{-1}\right)(p<0.01) \mathrm{TSH}$ compared to control treatment $\left(77.4 \pm 8.9 \mathrm{nmol} \cdot \mathrm{mg}^{-1} \cdot \mathrm{min}^{-1}\right)$.

\section{TSH inhibited the expression of SERCA2a via the PKA/PLN pathway}

To explore the cell signaling pathway involved in the downregulation of SERCA2a in cardiomyocytes, we treated the cells with various concentrations $(0,2,4$, or $8 \mu \mathrm{M})$ of TSH for 48 hours and measured PKA, P-PKA, PLN, P-PLN, and SERCA2a protein levels using western blots. TSH dose-dependently decreased P-PKA, P-PLN, and SERCA2a protein levels, but not PKA or PLN levels (Figure 4).

Similarly, treatment with a PKA inhibitor (H89) dramatically reduced P-PLN and SERCA2a mRNA (Figure 5a) and protein (Figure 5b) levels in NRCMs. To evaluate whether TSH suppressed SERCA2a by inhibiting Ser16 phosphorylation in PLN, we treated the cells with TSH and H89 simultaneously. This treatment decreased P-PLN and SERCA2a mRNA and protein levels as

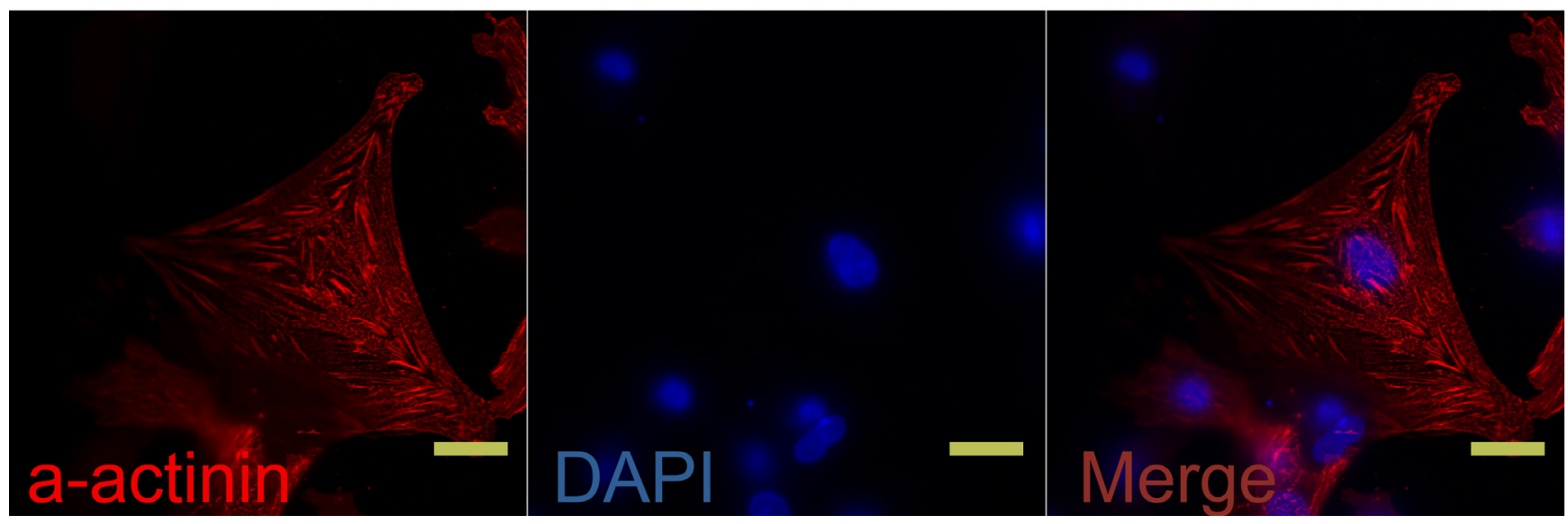

Figure 1: Isolated rat neonatal cardiomyocytes were stained with $\alpha$-actinin antibody (FITC-conjugated). Nuclei were visualized with DAPI staining (blue). $N=6$ per group. Scale bar, $20 \mu \mathrm{m}$. 
measured by PCR and western blot (Figure 5a, 5b). These results suggest that TSH decreases P-PLN and sesrca2a levels in NRCMs through a PKA-dependent pathway.

\section{DISCUSSION}

TSH receptors (TSHRs) are primarily expressed in thyroid follicular cells, and their activation by $\mathrm{TSH}$

\section{a.}
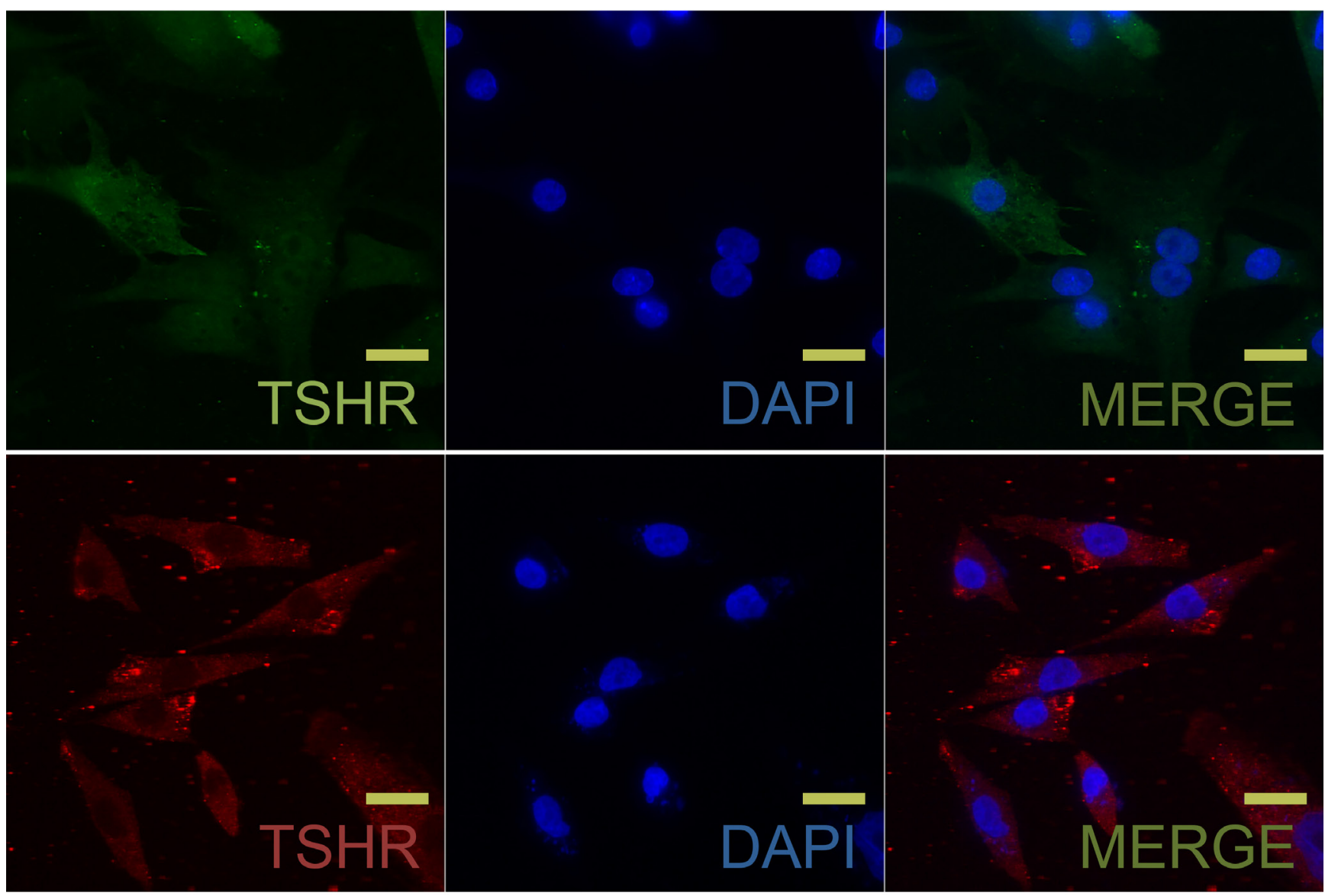

b.

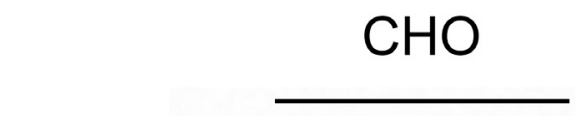

TSHR

\section{gapdh}

Figure 2: TSH receptor (TSHR) was expressed in neonatal rat ventricular myocytes (NRCM) and FRTL-5 cells. GAPDH was used as an internal reference. a. TSHR was visualized using immunofluorescence in NRCM and TFRTL-5 cells. Upper, TSHR (cy3-conjugated) was localized at NRCM cell membranes. Lower, TSHR (FITC-conjugated) was localized at FRTL-5 cell membranes. Nuclei were visualized with DAPI staining (blue). $N=6$ per group. Scale bar, $20 \mu \mathrm{m}$. b. TSHR protein levels in NRCMs were measured with western blots. Chinese Hamster Ovary (CHO) and FRTL-5 cells were used as negative and positive controls, respectively. $N=3$ per group. 
a.

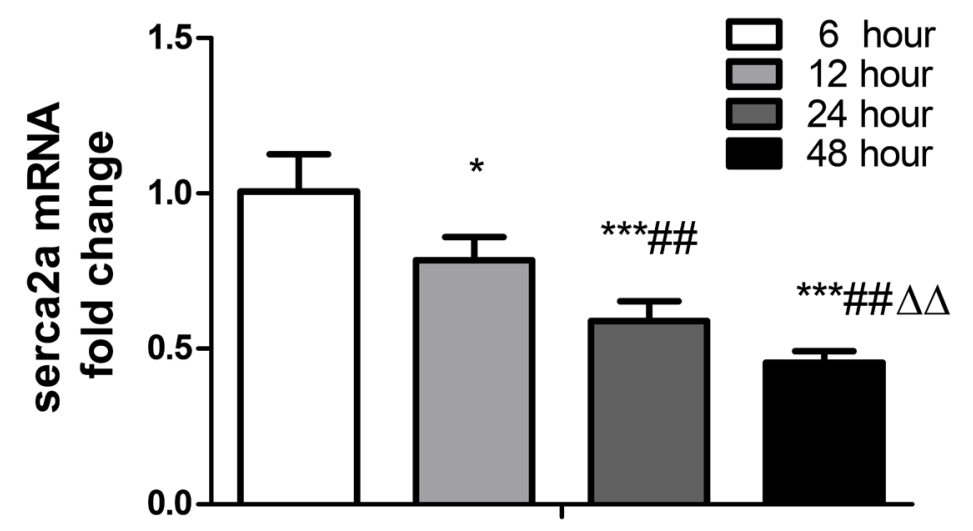

b.

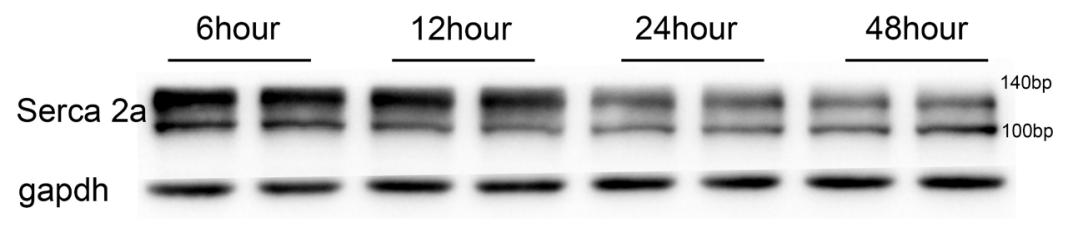

C.

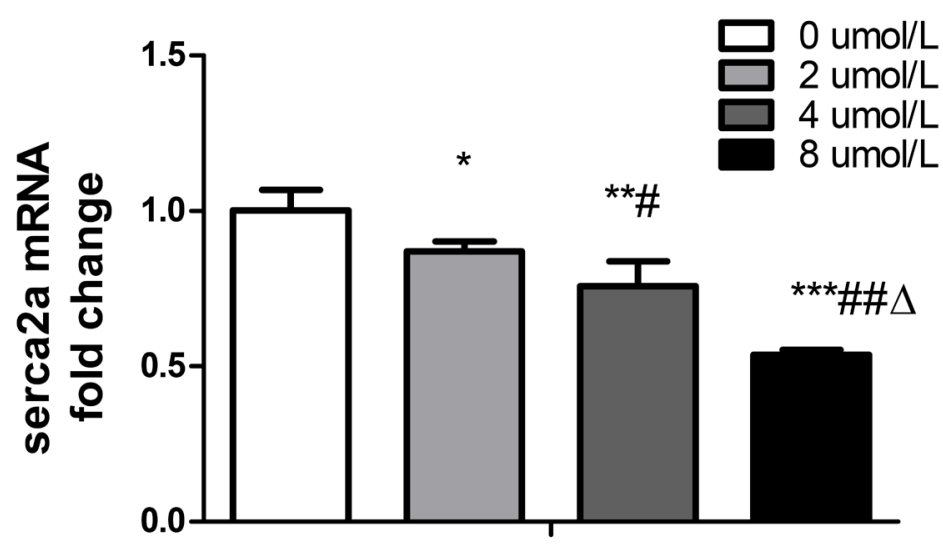

d.

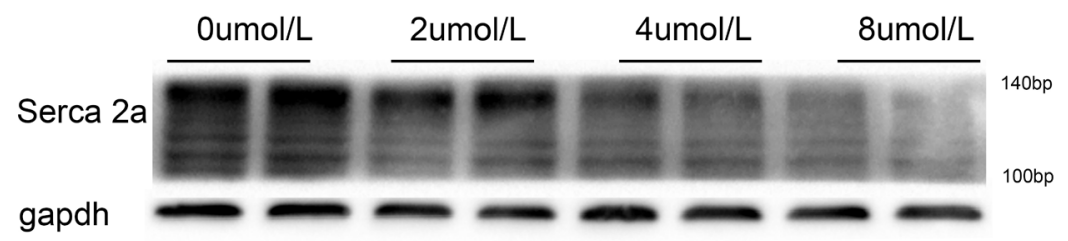

Figure 3: SERCA2a expression after treatment with different concentrations of TSH for different periods of time was measured in cardiomyocytes. GAPDH was used as an internal reference. SERCA2a mRNA a. and protein b. levels were measured after treatment with $4 \mu \mathrm{M}$ TSH for $6,12,24$, or 48 hours. ${ }^{*} p<0.05,{ }^{* * *} p<0.001$ versus control; \#\#p $<0.01$ versus 12 -hour group; $\Delta \Delta p$ $<0.01$ versus 24-hour group. SERCA2a mRNA c. and protein (d) levels after treatment with $0,2,4$, or $8 \mu \mathrm{M}$ TSH for 48 hours. ${ }^{*} p<0.05$ , ${ }^{* *} p<0.01,{ }^{* * *} p<0.001$ versus $0 \mu \mathrm{M} \mathrm{TSH}$. $\# p<0.05$, \#\#p $<0.01$ versus $2 \mu \mathrm{M}$ group. $\Delta p<0.05$ versus $4 \mu \mathrm{M}$ group. $\mathrm{N}=6$ per group for qPCRs and $\mathrm{N}=3$ per group for western blots. $\mu \mathrm{M}: \mu \mathrm{mol} / \mathrm{L}$. 
regulates the growth and functions of these cells. TSHRs are also present in extra-thyroidal cells, such as hepatocytes [12], lymphocytes [13], adipocytes [14], and retroocular fibroblasts [15]. Classic receptor binding studies demonstrated that TSHRs are also present in cardiac muscle $[16,17]$, and a recent study showed that TSHRs are expressed in H9C2 cells as well [18].

In this study, we extracted high-quality protein from NRCM cells and utilized optimized antibodies and western blots to investigate the presence of TSHRs and the mechanisms by which TSH regulates myocardial function. Western blot and immunofluorescence data indicated that TSHRs expressed in ventricular myocytes and provided important insights into pathophysiological roles of TSH in cardiac function.

In initial experiments, we used $\mathrm{H} 9 \mathrm{C} 2$ cells to investigate TSH-induced cardiac damage. However, TSH did not affect $\mathrm{H} 9 \mathrm{C} 2$ cell function. This may be due to the lack of automobile pulsing activity in $\mathrm{H} 9 \mathrm{C} 2$ cells, which limited their use as a model for investigating pathological processes in the heart in this study.

The contractile function of cardiomyocytes is controlled by excitation-contraction (EC) coupling. During this process, calcium is removed from the cytosol; approximately $30 \%$ is transported out of the cell (primarily by the sodium-calcium exchanger [NCX] and plasma membrane calcium ATPase [PMCA]), while $70 \%$ is pumped back into the sarcoplasmic reticulum by the cardiac sarcoplasmic reticulum calcium ATPase (SERCA2a) [19]. SERCA2a is crucial for restoring cytosolic calcium concentrations during cardiac relaxation and contraction in cardiomyocytes $[20,21]$.

Perturbations of calcium homeostasis stemming from altered expression or function of calcium transport or binding proteins like SERCA2a are central to the development of systo-diastolic dysfunction [22, 23]. Additionally, the heart is the major target organ for thyroid disease. Recent clinical trials have shown an association between subtle systolic dysfunction and impaired LV diastolic function in SHT patients [24]. It is possible that these abnormalities in cardiac systo-diastolic function in sHT often result from $\mathrm{TSH}$-induced alterations in SERCA2a expression.

Here, we observed that TSH dose- and timedependently downregulated the activity and expression of SERCA2a mRNA and protein in cardiomyocytes. Longterm increases in TSH may therefore lead to subtle systolic dysfunction and damaged LV diastolic function in sHT patients by altering SERCA2a activity and cellular calcium transport. Moreover, recent evidence suggests that rising serum TSH levels might contribute to the development of sHT $[9,25]$. Elevated TSH levels may contribute to cardiac dysfunction throughout the development and progression of hypothyroidism by initiating cardiomyocyte dysfunction in early-stage subclinical hypothyroidism and promoting subsequent pathological changes during later stages.

The small phosphoprotein phospholamban (PLN) modulates SERCA2a activity in cardiac muscle. Recent studies have revealed that sarcolipin (SLN), another small molecular weight protein, is also involved in SERCA2a regulation [26]. PLN expression is higher in the ventricle, which was the source of the cells used here [27], while SLN levels are higher in the atria [2831]. PLN, a single-span membrane protein of only 52 amino acids, decreases the $\mathrm{Ca}^{2+}$ affinity of SERCA2a

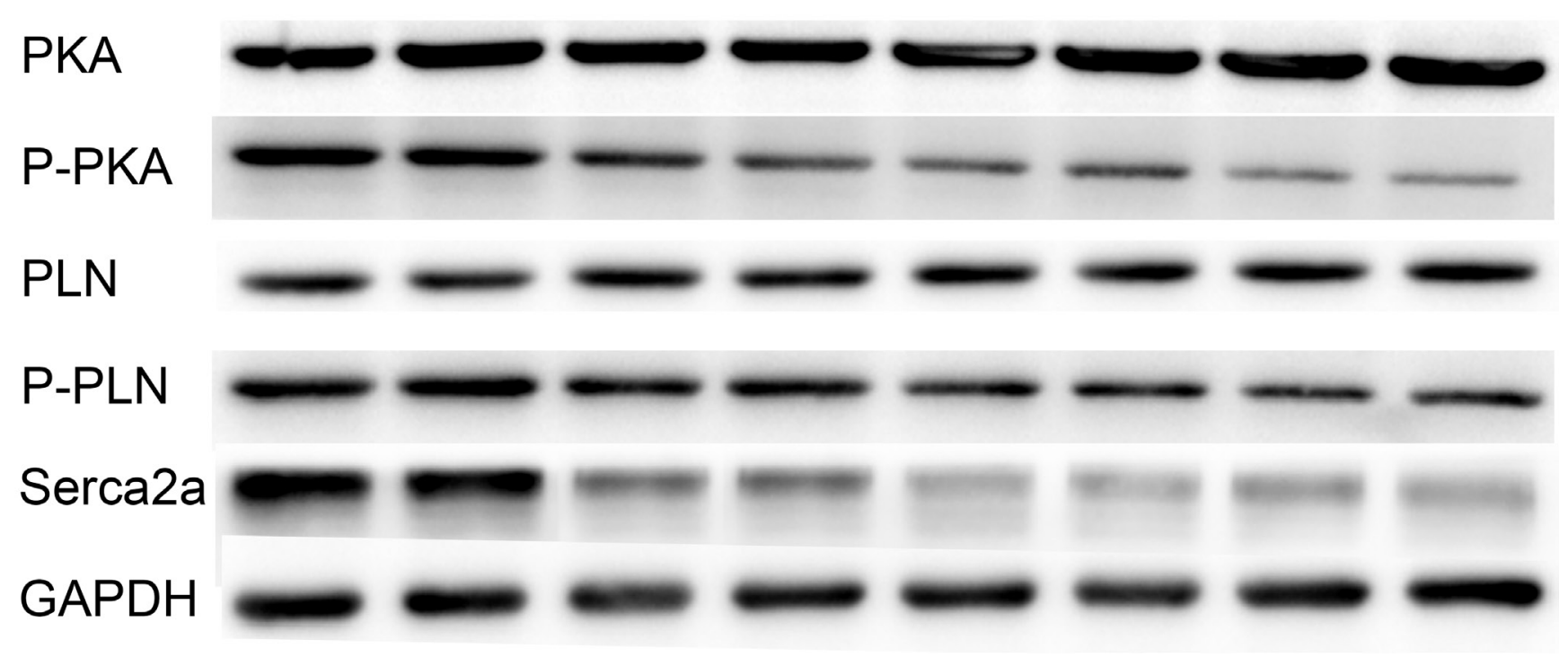

Figure 4: TSH inhibits SERCA2a expression by inhibiting the PKA/PLN pathway. GAPDH was used as an internal reference. $N=3$ per group. PKA: protein kinase A; PLN: phoshpolamban. 
and attenuates contractile strength in the heart. PLN in turn is regulated by phosphorylation/dephosphorylation. In its dephosphorylated form, PLN binds SERCA2a and actively inhibits $\mathrm{Ca}^{2+}$-transport [32], and phosphorylation of PLN reverses this inhibition. PLN has two distinct phosphorylation sites: threonine 17, which is phosphorylated by $\mathrm{Ca}^{2+}$-calmodulin-dependent protein kinase (CaMKII) during $\beta$-adrenergic stimulation, and serine 16 , which is phosphorylated by cAMP-dependent protein kinase (PKA) $[33,34]$. Data from several studies show that reduced Ser16 phosphorylation correlates with reduced sensitivity of SERCA2a to high $\mathrm{Ca}^{2+}$ levels and leads to decreased myocardial contractility and relaxation abnormalities $[35,36]$. Moreover, Ser16 phosphorylation is independent of CaMKII-dependent Thr17 phosphorylation, whereas the latter is dependent on preceding phosphorylation of Ser16 [15, 37]. Thus, Thr17 phosphorylation does not affect baseline PLN phosphorylation in normal tissues [38, 39]; we therefore focused on PKA-dependent phosphorylation of PLN at Ser16.
Here, we found that the PKA inhibitor H89 reduced PLN phosphorylation and SERCA2a expression, indicating that the regulation of P-PLN and SERCA2a is PKA-dependent. Co-treatment with TSH and H89 also inhibited the expression of P-PLN and SERCA2a in NRCMs. Furthermore, western blots confirmed that TSH dose-dependently decreased P-PKA, P-PLN, and SERCA2a protein levels. These data strongly suggest that TSH inhibits ventricular P-PLN and SERCA2a expression by inhibiting the PKA/PLN signaling pathway.

In summary, cardiomyocytes, which exhibit physiopathological responses nearly identical to those observed in the heart, were used as an in vitro model of cardiac function. We showed that TSHRs are expressed in cardiomyocytes and that TSH downregulated SERCA2a by inhibiting the PKA/PLN signaling pathway in these cells. Abnormally high serum TSH levels may therefore influence cardiovascular system function and may be useful as an independent risk factor for cardiovascular complications in hypothyroidism.

\section{a.}
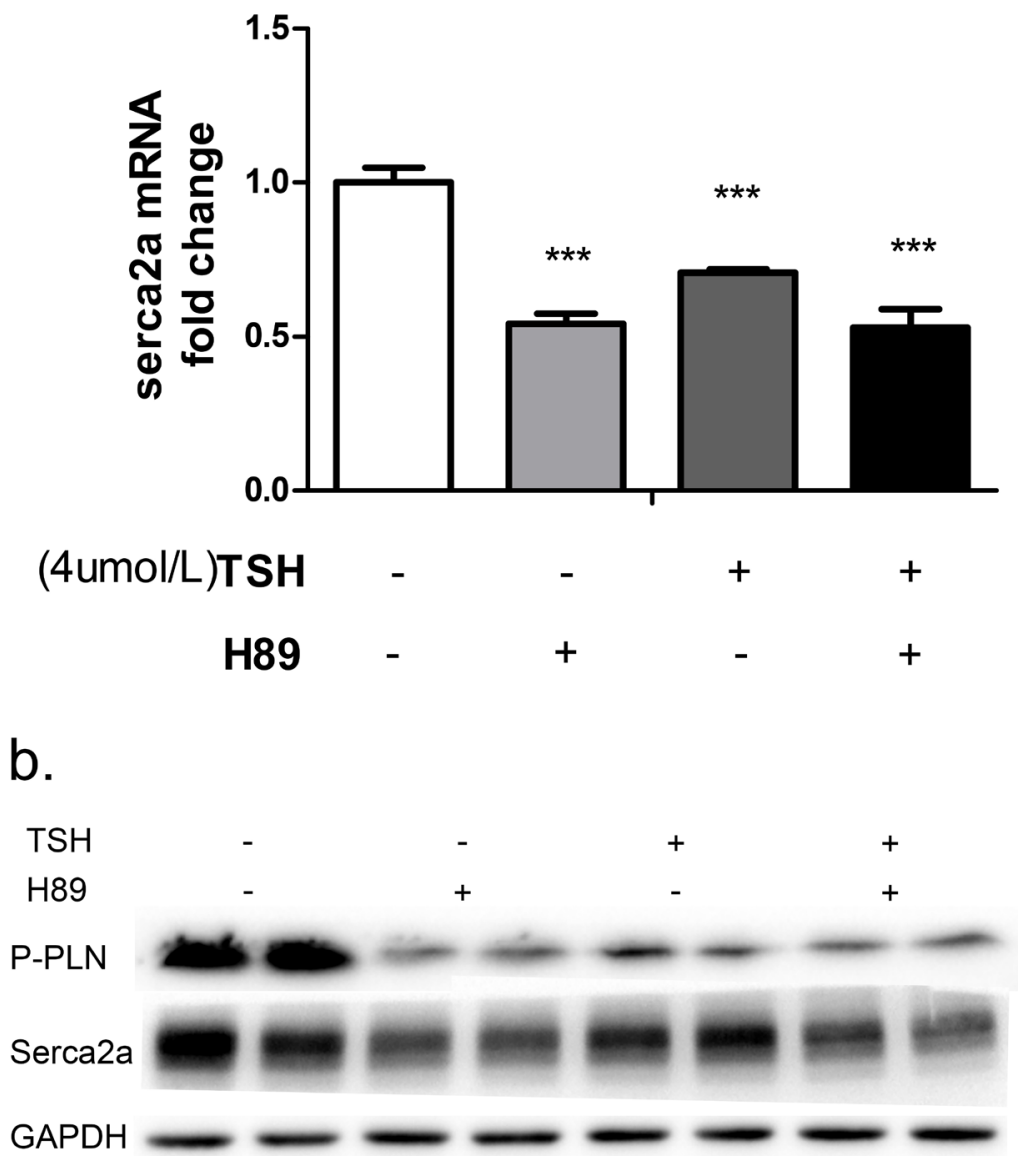

Figure 5: NRCMs were treated with $4 \boldsymbol{\mu M}$ TSH and $20 \boldsymbol{\mu M} \mathbf{H 8 9}$ for 24 hours. Changes in PKA/PLN pathway molecules and SERCA2a were measured with real-time PCR a. and western blot b. ${ }^{* * *} p<0.001$ versus control. GAPDH was used for normalization. $N$ $=6$ per group for qPCRs and $N=3$ per group for western blots. 


\section{MATERIALS AND METHODS}

This experiment was approved by the ethical committees of the Nanjing Medical University, and all animal studies were completed in accordance with the recommendations of the Declaration of Helsinki and international standards regarding the use and care of laboratory animals.

\section{Neonatal rat cardiomyocyte isolation and culture}

A principal culture of neonatal rat cardiomyocytes (NRCM) was obtained from the ventricles of 1-3 day old Wistar rats by enzymatic disassociation. Rats received heart surgery under $0.1 \mathrm{~mL}$ of $5 \%$ chloral hydrate anesthesia injected intraperitoneally. The atria and large vessels were removed from the detached hearts, which were then washed in 1x ADS solution (200 mL 10x ADS: $13.6 \mathrm{~g} \mathrm{NaCl} ; 9.52 \mathrm{~g}$ HEPES; $0.276 \mathrm{~g} \mathrm{Na}_{2} \mathrm{HPO}_{4} ; 1.2 \mathrm{~g}$ glucose; $0.8 \mathrm{~g} \mathrm{KCl} ; 0.0102 \mathrm{~g} \mathrm{MgSO}_{4} ; 200 \mathrm{~mL} \mathrm{H}_{2} \mathrm{O}$, pH: 7.35-7.45). Cardiac cells were dispersed by a series of incubations at $37^{\circ} \mathrm{C}$ in $0.6 \mathrm{mg} / \mathrm{mL}$ pancreatin (SigmaAldrich Co., St. Louis, Missouri LLC. USA) and $0.5 \mathrm{mg} /$ $\mathrm{mL}$ type II collagenase (Worthington, Lakewood, NJ, USA). The dispersed cells were plated differentially for 2 hours to reduce fibroblast contamination. Unattached cardiomyocytes were then seeded on $1 \%$ gelatin-coated plates in medium containing $10 \%$ horse serum, $5 \%$ fetal calf serum (Gibco Pasadena, CA, USA), and 5-Bromo2'-Deoxyuridine (BRDU) (Sigma-Aldrich Co., St. Louis, Missouri, USA) ( $3 \mathrm{mg} / \mathrm{mL})$ to further suppress fibroblasts. Twenty hours after plating, cells were transferred into serum-free medium to remove endogenous hormones and growth factors and then treated with or without various concentrations of bTSH (Sigma-Aldrich Co., St. Louis, Missouri, USA) for different periods of time. FRTL-5 rat thyroid cells were cultured at $37^{\circ} \mathrm{C}$ in a $5 \% \mathrm{CO}_{2}$ humidified atmosphere in high-glucose DMEM supplemented with $10 \%$ fetal bovine serum (FBS), $100 \mathrm{U} / \mathrm{ml}$ penicillin, and $100 \mathrm{mg} / \mathrm{mL}$ streptomycin (Gibco Pasadena, CA, USA). These cells were utilized as the positive control in this study. The $\mathrm{CHO}$ cell line was cultured as previously described and served as a negative control.

\section{SERCA2a activity}

The cardiomyocytes were lysed in $100 \mu \mathrm{L}$ RIPA buffer (Beyotime Institute of Biotechnology) including a protease inhibitor cocktail (Sigma, St. Louis, MO, USA). The supernatant was then filtered by centrifuging at $12000 \mathrm{rpm}$ for $15 \mathrm{~min}$ at $4^{\circ} \mathrm{C}$. The protein was mixed with $10 \%$ sucrose buffer containing $0.5 \mathrm{mM} \mathrm{MgCl}, 400$ $\mathrm{mM} \mathrm{KCl}, 0.5 \mathrm{mM}$ EGTA, $0.5 \mathrm{mM} \mathrm{CaCl}$, and $25 \mathrm{mM}$ PIPES, $\mathrm{pH}$ 7.0. SERCA2a activity assays were based on a pyruvate/NADH coupled reaction. SERCA2a activity was calculated as $\Delta$ absorbance/(6.22 $\times$ protein $\times$ time $)$ in $\mathrm{nmol}$ $\mathrm{ATP} /(\mathrm{mg}$ protein $\times \min )[10]$.

\section{Quantitative RT-PCR}

Total RNAs were isolated using RNAprep pure Cell/Bacteria Kit (TianGen, Beijing, China). To detect the expression of protein-coding genes by quantitative RT-PCR, 800 ng RNA samples were reverse-transcribed to cDNA with a Bio-Rad iScripTM cDNA Synthesis Kit (Bio-Rad, Hercules, CA, USA) according to the manufacturer's instructions in a reaction volume of $20 \mu \mathrm{L}$. The PCR protocol consisted of 3 minutes of denaturation at $95^{\circ} \mathrm{C}$ followed by 40 cycles of $95^{\circ} \mathrm{C}$ for 15 seconds, $60^{\circ} \mathrm{C}$ for 30 seconds, and $72^{\circ} \mathrm{C}$ for 30 seconds using the $\mathrm{iQ}^{\mathrm{TM}} \mathrm{SYBR}^{\circledR}$ Green supermixes (Bio-Rad, Hercules, CA, USA) in the 7900HT Fast Real-Time PCR System. Relative mRNA expression was calculated using the $2^{-\Delta \Delta C t}$ method. The mRNA expression was normalized to GAPDH expression. The following primer sets were used for this experiment:

Table 1: Primer sequences used for real-time PCR

\begin{tabular}{|l|l|l|l|}
\hline Gene & Primer sequence & $\begin{array}{l}\text { Product } \\
\text { (bp) }\end{array}$ & $\begin{array}{l}\text { Gene } \\
\text { bank }\end{array}$ \\
\hline RatSERCA2a & $\begin{array}{l}\text { 5'-GGAGGCGTTGCTAAACACTC-3' } \\
\text { 5'-GAACCAGCCTTCGATATTGG-3' }\end{array}$ & 201 & $\begin{array}{l}\text { AY- } \\
948198\end{array}$ \\
\hline RatGAPDH & $\begin{array}{l}\text { 5'-GGCACAGTCAAGGCTGAGAA-3' } \\
\text { 5-ATGGTGGTGAAGACGCCAGT-3' }\end{array}$ & 143 & $\begin{array}{l}\text { NM- } \\
017008\end{array}$ \\
\hline
\end{tabular}

\section{Western blotting}

Cardiac cells were lysed by $12,000 \times \mathrm{g}$ centrifugation for 15 min at $4^{\circ} \mathrm{C}$ in RIPA buffer (Beyotime Institute of Biotechnology) including a protease inhibitor cocktail (Sigma, St. Louis, MO, USA). Protein concentration was determined using a BCA Protein Assay Kit (Thermo Fisher Scientific, USA). Subsequently, samples were separated by SDS/PAGE and transferred to PVDF membranes which were incubated overnight at $4^{\circ} \mathrm{C}$ in $5 \%$ BSA with the following antibodies: Calcium Ion Regulation Antibody Sampler Kit (Cell Signaling Technology, Boston, Massachusetts, USA) (1:1,000); GAPDH (Abcam, Cambrige, UK) (1:1,000); and anti-TSHR (Santa Cruz Biotechnology, Dallas, TX, USA) (1:100). Samples were then washed three times with TBST buffer before adding secondary antibody. Using the ChemiDoc XRS Plus luminescent image analyzer (Bio-Rad, Hercules, CA, USA), specific protein bands were visualized using ECL Plus Western blot detection reagents (Bio-Rad). Densitometric analysis of band intensity was completed using Imagelab software (Bio-Rad, Hercules, CA, USA). 


\section{Immunofluorescent microscopy}

After the appropriate treatment, NRCMs were fixed with $4 \%$ paraformaldehyde for $20 \mathrm{~min}$, then washed twice with PBS. Cells were permeabilized by incubation in $0.2 \%$ Triton X-100 in PBS for 20 min and incubated in 10\% normal goat serum for 1 hour to block nonspecific binding. The samples were then incubated overnight at $4^{\circ} \mathrm{C}$ with the appropriate primary antibody, all of which were diluted with 10\% normal goat serum: anti-actinin (Sigma, St. Louis, MO) (1:500), SERCA2a (Abcam, Cambrige, UK) (1:500), or anti-TSHR (1:50). Subsequently, the cells were incubated with secondary antibody at $37^{\circ} \mathrm{C}$ for 2 hours and the nuclei were stained with DAPI (Vector Laboratories, Burlingame, CA, USA). Cell images were captured using a confocal laser scanning microscope (CarlZeiss LSM710, Germany). All images were obtained using the same intensity and photo detector gain settings to allow quantitative comparison of immunoreactivity.

\section{Statistical analysis}

One-way analysis of variance (ANOVA) and $t$-tests were conducted for statistical analysis using Graphpad Prism 5 software. Data are expressed as mean \pm SE. A $p$ value of $<0.05$ was considered significant.

\section{ACKNOWLEDGMENTS}

This research was supported by grants from National Natural Science Foundation of China (81360125). The authors gratefully acknowledge the staff of the Department of Cardiology of Jiangsu Province Hospital for their technical assistance. We also thank Tao Lichan, Shen Shutong, Li Shanshan, Zhang Xiaomin, and Wu Xiaoting for their assistance. Grateful thanks to professor William Goldman for his helpful revision.

\section{CONFLICTS OF INTEREST}

None declared.

\section{REFERENCES}

1. Klein I, Danzi S. Thyroid disease and the heart. Circulation. 2007; 116:1725-1735.

2. Arem R, Rokey R, Kiefe C, Escalante DA, Rodriguez A. Cardiac systolic and diastolic function at rest and exercise in subclinical hypothyroidism: effect of thyroid hormone therapy. Thyroid. 1996; 6:397-402.

3. Tognini S, Pasqualetti G, Calsolaro V, Polini A, Caraccio $\mathrm{N}$, Monzani F. Cardiovascular risk and quality of life in elderly people with mild thyroid hormone deficiency. Frontiers in endocrinology. 2014; 5:153.
4. Brenta G, Mutti LA, Schnitman M, Fretes O, Perrone A, Matute ML. Assessment of left ventricular diastolic function by radionuclide ventriculography at rest and exercise in subclinical hypothyroidism, and its response to L-thyroxine therapy. The American journal of cardiology. 2003; 91:1327-1330.

5. Di Bello V, Monzani F, Giorgi D, Bertini A, Caraccio N, Valenti G, Talini E, Paterni M, Ferrannini E, Giusti C. Ultrasonic myocardial textural analysis in subclinical hypothyroidism. Journal of the American Society of Echocardiography. 2000; 13:832-840.

6. Monzani F, Di Bello V, Caraccio N, Bertini A, Giorgi D, Giusti C, Ferrannini E. Effect of levothyroxine on cardiac function and structure in subclinical hypothyroidism: a double blind, placebo-controlled study. The Journal of clinical endocrinology and metabolism. 2001; 86:11101115 .

7. Vitale G, Galderisi M, Lupoli GA, Celentano A, Pietropaolo I, Parenti N, De Divitiis O, Lupoli G. Left ventricular myocardial impairment in subclinical hypothyroidism assessed by a new ultrasound tool: pulsed tissue Doppler. The Journal of clinical endocrinology and metabolism. 2002; 87:4350-4355.

8. Aghini-Lombardi F, Di Bello V, Talini E, Di Cori A, Monzani F, Antonangeli L, Palagi C, Caraccio N, Grazia Delle Donne M, Nardi C, Dardano A, Balbarini A, Mariani M, Pinchera A. Early textural and functional alterations of left ventricular myocardium in mild hypothyroidism. European journal of endocrinology. 2006; 155:3-9.

9. Caraccio N, Natali A, Sironi A, Baldi S, Frascerra S, Dardano A, Monzani F, Ferrannini E. Muscle metabolism and exercise tolerance in subclinical hypothyroidism: a controlled trial of levothyroxine. The Journal of clinical endocrinology and metabolism. 2005; 90:4057-4062.

10. del Monte F, Williams E, Lebeche D, Schmidt U, Rosenzweig A, Gwathmey JK, Lewandowski ED, Hajjar RJ. Improvement in Survival and Cardiac Metabolism After Gene Transfer of Sarcoplasmic Reticulum Ca2+-ATPase in a Rat Model of Heart Failure. Circulation. 2001; 104:14249.

11. Lazarides E, Burridge K. Alpha-actinin: immunofluorescent localization of a muscle structural protein in nonmuscle cells. Cell. 1975; 6:289-298.

12. Zhang W, Tian LM, Han Y, Ma HY, Wang LC, Guo J, Gao L, Zhao JJ. Presence of thyrotropin receptor in hepatocytes: not a case of illegitimate transcription. Journal of cellular and molecular medicine. 2009; 13:4636-4642.

13. Paschke R, Geenen V. Messenger RNA expression for a TSH receptor variant in the thymus of a two-year-old child. Journal of molecular medicine. 1995; 73:577-580.

14. Endo T, Ohta K, Haraguchi K, Onaya T. Cloning and functional expression of a thyrotropin receptor cDNA from rat fat cells. The Journal of biological chemistry. 1995; 270:10833-10837. 
15. Luo W, Chu G, Sato Y, Zhou Z, Kadambi VJ, Kranias EG. Transgenic approaches to define the functional role of dual site phospholamban phosphorylation. The Journal of biological chemistry. 1998; 273:4734-4739.

16. Drvota V, Janson A, Norman C, Sylven C, Haggblad J, Bronnegard M, Marcus C. Evidence for the presence of functional thyrotropin receptor in cardiac muscle. Biochemical and biophysical research communications. 1995; 211:426-431.

17. Sellitti DF, Hill R, Doi SQ, Akamizu T, Czaja J, Tao S, Koshiyama H. Differential expression of thyrotropin receptor mRNA in the porcine heart. Thyroid. 1997; 7:641646.

18. Huang W, Xu J, Jing F, Chen WB, Gao L, Yuan HT, Zhao JJ. Functional thyrotropin receptor expression in the ventricle and the effects on ventricular BNP secretion. Endocrine. 2014; 46:328-339.

19. Gorski PA, Ceholski DK, Hajjar RJ. Altered myocardial calcium cycling and energetics in heart failure-a rational approach for disease treatment. Cell metabolism. 2015; 21:183-194.

20. Anger M, Lompre AM, Vallot O, Marotte F, Rappaport L, Samuel JL. Cellular distribution of $\mathrm{Ca} 2+$ pumps and $\mathrm{Ca} 2+$ release channels in rat cardiac hypertrophy induced by aortic stenosis. Circulation. 1998; 98:2477-2486.

21. Huke S, Liu LH, Biniakiewicz D, Abraham WT, Periasamy M. Altered force-frequency response in non-failing hearts with decreased SERCA pump-level. Cardiovascular research. 2003; 59:668-677.

22. Bers DM. Cardiac excitation-contraction coupling. Nature. 2002; 415:198-205.

23. van der Velden J. Diastolic myofilament dysfunction in the failing human heart. Pflugers Archiv. 2011; 462:155-163.

24. Fazio S, Palmieri EA, Lombardi G, Biondi B. Effects of thyroid hormone on the cardiovascular system. Recent progress in hormone research. 2004; 59:31-50.

25. Monzani F, Caraccio N, Siciliano G, Manca L, Murri L, Ferrannini E. Clinical and biochemical features of muscle dysfunction in subclinical hypothyroidism. The Journal of clinical endocrinology and metabolism. 1997; 82:33153318.

26. Bhupathy P, Babu GJ, Periasamy M. Sarcolipin and phospholamban as regulators of cardiac sarcoplasmic reticulum $\mathrm{Ca} 2+$ ATPase. Journal of molecular and cellular cardiology. 2007; 42:903-911.

27. Koss KL, Ponniah S, Jones WK, Grupp IL, Kranias EG. Differential phospholamban gene expression in murine cardiac compartments. Molecular and physiological analyses. Circulation research. 1995; 77:342-353.

28. Babu GJ, Zheng Z, Natarajan P, Wheeler D, Janssen PM, Periasamy M. Overexpression of sarcolipin decreases myocyte contractility and calcium transient. Cardiovascular research. 2005; 65:177-186.
29. Minamisawa S, Wang Y, Chen J, Ishikawa Y, Chien KR, Matsuoka R. Atrial chamber-specific expression of sarcolipin is regulated during development and hypertrophic remodeling. The Journal of biological chemistry. 2003; 278:9570-9575.

30. Vangheluwe P, Schuermans M, Zador E, Waelkens E, Raeymaekers L, Wuytack F. Sarcolipin and phospholamban mRNA and protein expression in cardiac and skeletal muscle of different species. The Biochemical journal. 2005; 389:151-159.

31. Vangheluwe P, Sipido KR, Raeymaekers L, Wuytack F. New perspectives on the role of SERCA2's Ca2+ affinity in cardiac function. Biochimica et biophysica acta. 2006; 1763:1216-1228.

32. Tada M, Ohmori F, Yamada M, Abe H. Mechanism of the stimulation of $\mathrm{Ca} 2+$-dependent ATPase of cardiac sarcoplasmic reticulum by adenosine 3 ':5'-monophosphatedependent protein kinase. Role of the 22,000-dalton protein. The Journal of biological chemistry. 1979; 254:319-326.

33. Fujii J, Zarain-Herzberg A, Willard HF, Tada M, MacLennan DH. Structure of the rabbit phospholamban gene, cloning of the human cDNA, and assignment of the gene to human chromosome 6 . The Journal of biological chemistry. 1991; 266:11669-11675.

34. Moon MR, Aziz A, Lee AM, Moon CJ, Okada S, Kanter EM, Yamada KA. Differential calcium handling in two canine models of right ventricular pressure overload. The Journal of surgical research. 2012; 178:554-562.

35. Sande JB, Sjaastad I, Hoen IB, Bokenes J, Tonnessen T, Holt E, Lunde PK, Christensen G. Reduced level of serine(16) phosphorylated phospholamban in the failing rat myocardium: a major contributor to reduced SERCA2 activity. Cardiovascular research. 2002; 53:382-391.

36. Schwinger RH, Munch G, Bolck B, Karczewski P, Krause EG, Erdmann E. Reduced $\mathrm{Ca}(2+)$-sensitivity of SERCA $2 \mathrm{a}$ in failing human myocardium due to reduced serin-16 phospholamban phosphorylation. Journal of molecular and cellular cardiology. 1999; 31:479-491.

37. Bilezikjian LM, Kranias EG, Potter JD, Schwartz A. Studies on phosphorylation of canine cardiac sarcoplasmic reticulum by calmodulin-dependent protein kinase. Circulation research. 1981; 49:1356-1362.

38. Kuschel M, Karczewski P, Hempel P, Schlegel WP, Krause EG, Bartel S. Ser16 prevails over Thr17 phospholamban phosphorylation in the beta-adrenergic regulation of cardiac relaxation. The American journal of physiology. 1999; 276:H1625-1633.

39. Said M, Mundina-Weilenmann C, Vittone L, Mattiazzi A. The relative relevance of phosphorylation of the $\operatorname{Thr}(17)$ residue of phospholamban is different at different levels of beta-adrenergic stimulation. Pflugers Archiv 2002; 444:801809. 